\title{
Unveiling the Synthesis of Spirocyclic, Tricyclic and Bicyclic Triazolooxazines From Intramolecular [3+2] Azide-alkyne Cycloadditions With a Molecular Electron Density Theory Perspective
}

Nivedita Acharjee ( $\nabla$ nivchem@gmail.com )

Durgapur Government College https://orcid.org/0000-0001-8354-8693

Haydar A Mohammad-Salim

University of Zakho

Mrinmoy Chakraborty

Dr BC Roy Engineering College

\section{Research Article}

Keywords: Molecular Electron Density Theory, Azide-alkyne cycloadditions, Intramolecular, Transition State

Posted Date: December 8th, 2021

DOI: https://doi.org/10.21203/rs.3.rs-1122676/v1

License: (c) (1) This work is licensed under a Creative Commons Attribution 4.0 International License. Read Full License

Version of Record: A version of this preprint was published at Structural Chemistry on January 24th, 2022. See the published version at https://doi.org/10.1007/s11224-021-01870-3. 


\section{Abstract}

The intramolecular [3+2] cycloaddition (32CA) reactions of azido alkynes leading to spirocyclic, tricyclic and bicyclic triazolooxazines has been studied within the molecular electron density theory (MEDT) at the MPWB1K/6-311G(d,p) level. The Electron localization function (ELF) characterizes the azido alkynes as zwitterionic species. Analysis of the Conceptual DFT indices allows classifying the azide moiety as the electrophilic counterpart and the alkyne as the nucleophilic one. These 32CA reactions are under kinetic control with the activation free energies of $23.4-26.7 \mathrm{kcal} \mathrm{mol}^{-1}$. Along the reaction path, the pseudoradical center is created initially at $\mathrm{C} 4$, consistent with the Parr function analysis, however the sequence of bond formation is controlled by the energetically feasible formation of the six membered oxazine ring. The intermolecular interactions at the TSs were characterized from the Quantum Theory of Atoms in Molecules (QTAIM) study and the Non covalent interaction ( $\mathrm{NCl}$ ) gradient isosurfaces.

\section{Introduction}

The azide (1) - alkyne (2) [3+2] cycloaddition (32CA) reactions (Scheme 1), studied by Huisgen [1, 2] in the 1960s, have served as the most prolific and successful synthetic pathways to 1,2,3-triazoles [3] since last five decades. Owing to numerous industrial [4] and pharmaceutical [5] applications, these 32CAs have been extensively utilized by the organic chemists to design new synthetic protocols. Among them is the click chemistry discovery of the copper catalyzed version, namely the CuAAC (copper catalyzed azide alkyne) reactions (Scheme 1), independently by Sharpless [6] and Meldal [7, 8] research groups during 2001-2002. The CuAAC reactions [9] show highly regioselective performance to generate 1,4-disubstituted 1,2,3-triazole (3) with remarkable acceleration in the reaction rate at a lower reaction temperature. Continuing with the metal catalyzed versions of azide-alkyne 32CAs, Fokin et al [10] reported the Ru(II) catalyzed reactions with exclusive regioselectivity leading to 1,5-disubstituted 1,2,3-triazole (4).

With no doubt, the metal catalyzed intermolecular version of the azide-alkyne 32CA reaction has widespread utility in the synthesis of high value-added organic products. However, the relatively unexplored intramolecular version is also worthwhile for the construction of unique heterocyclic structural scaffolds as reported by Dutta et al [11] in 2009. In 2010, Mazumdar et al [12] synthesized 1,2,3-triazole fused dibenzo [1, 5] diazocine derivatives from intramolecular azide-alkyne 32CAs. Very recently, in 2021, Mazur and coworkers [13] have reported the catalyst free intramolecular azide-alkyne 32CA reaction leading to 1,2,3-triazolobenzodiazepinones. The intramolecular 32CA reactions require strategic positioning of the azide and the alkyne functionalities in the same reagent to allow the appropriate structural framework for the cycloaddition. The 0-alkylation of azido alcohol $\mathbf{5}$ with a propargylic halides 6, 7 generates the so called "azido alkyne" reagent 8 which undergoes thermally induced intramolecular $32 \mathrm{CA}$ reaction to give the triazolooxazine 9 in quantitative yields (Scheme 2). Such reactions do not require metal induced catalysis and generally proceed with exclusive regioselectivity.

In 2018, Cobb et al [14] extended the scope of intramolecular azide alkyne 32CA reactions to synthesize the azido alkynes 10-12 and their intramolecular cyclization to spirocyclic triazolooxazines 13-15 with 
potent antiviral activity against MHV (Murine Hepatitis Virus) (Scheme 3). Dutta et al [11] installed the alkyne functionality in the cyclo azido alcohols to generate the azido alkyne 16 leading to the tricyclic tricyclooxazines 17 in quantitative yields (Scheme 3). They also reported the clean and complete conversion of azido alkyne 18 to bicyclic triazolooxazines 19 (Scheme 3).

Since the last five decades, analysis of organic reactions was based on the frontier molecular orbital (FMO) theory until in 2016 Domingo [15] proposed the molecular electron density theory (MEDT) as a promising alternative to study numerous organic reactions by identifying the role of electron density changes in the molecular reactivity. MEDT [15-17] has been applied successfully to study varied aspects of cycloaddition reactions since last five years such as strain promotion [18, 19], substituent effects [20, $21]$, chemo- [22, 23], stereo- and regioselectivity [24, 25], catalysis [26] etc.

In 2018, Ayouchia et al [27] reported a MEDT study for the thermally induced 32CA reactions of aryl azides and alkyne derivatives, while the $\mathrm{Cu}(\mathrm{I})$ catalyzed regioselective intermolecular azide-alkyne 32CA reaction leading to 1,4-disubstituted-1,2,3-triazoles was also analyzed in the same year by Ayouchia et al [28] with the MEDT perspective. Recently, in 2020, we have reported the MEDT studies for the Grignard reagent mediated regioselective intermolecular azide-alkyne 32CA leading to 1,5-disubstituted-1,2,3triazoles [29] and for the strain promoted azide-alkyne cycloadditions (SPAAC) [18] All of these theoretical analyses were devoted to the intermolecular 32CA reactions, while MEDT studies on intramolecular azidealkyne 32CA reactions have not been addressed so far.

Herein, we present the MEDT study for the intramolecular azide-alkyne 32CA reactions reported by Cobb et al [14] for the synthesis of antiviral spirocyclic triazolooxazines. The intramolecular 32CA reactions reported by Dutta et al [11] for the synthesis of bicyclic and tricyclic triazolooxazines have also been studied herein within the MEDT perspective to obtain a complete comprehension of the reactivity and mechanism of intramolecular azide-alkyne 32CA reactions.

This MEDT study has been presented in six sections (1) The conceptual density functional theory [30, 31] (CDFT) analysis at the ground state (GS) structures was performed to characterize the chemical behaviour and the electronic flux between the azide and alkyne moieties of the azido alkynes 10, 11, 12, 16 and 18. (2) the electron localization function [32, 33] (ELF) of these azido alkynes was analyzed to correlate the electronic structure and the molecular reactivity (3) the potential energy surfaces (PES) of the intramolecular 32CA reactions were followed to study the energy profile (4) the topological analysis of the ELF at the TSs and along the reaction path was performed to structure the plausible mechanism (5) finally, the interactions at the TSs were characterized by analyzing the Quantum theory of Atoms-in Molecules (QTAIM) parameters [34,35] and the non-covalent interaction ( $\mathrm{NCl}$ ) gradient isosurfaces [36].

\section{Computational Methods}

\section{Computational Methods}

The Berny analytical gradient optimization method [37] was used to optimize the azido alkynes, TSs and triazolooxazines using the MPWB1K [38] functional with the 6-311G $(\mathrm{d}, \mathrm{p})$ basis set [39]. The use of 
MPWB1K functional has been recommended in several recent studies [16-24] as a precise computational level to study 32CA reactions. The located TSs were verified by the presence of one imaginary frequency, while the minima were verified by the absence of imaginary frequency. The minimum energy reaction pathway between the azido alkynes, TSs and triazolooxazines were verified from the intrinsic reaction coordinate (IRC) calculations [40-42].

The electronic chemical potential $[30,31,43] \mu$, chemical hardness $[30,31,44] \eta$, electrophilicity index [30, $31,45] \omega$ and nucleophilicity $N$ index $[30,31,46]$ were calculated from the HOMO ( $\left.E_{\text {HOMO }}\right)$ and LUMO ( $\left.E_{\mathrm{LUMO}}\right)$ energies by Eq-(1) to (4)

$\mu \approx\left(E_{\mathrm{HOMO}}+E_{\mathrm{LUMO}}\right) / 2(\mathbf{1})$

$\eta \approx E_{\mathrm{LUMO}}-E_{\mathrm{HOMO}}(2)$

$\omega=\mu^{2} / 2 \eta(3)$

$N=E_{\mathrm{HOMO}}-E_{\mathrm{HOMO}(\text { tetracyanoethylene) }}(4)$

The electrophilic and nucleophilic Parr functions [47] are calculated from the Mulliken atomic spin densities (MASD) of radical anion $\left[\rho_{s}^{r a}(r)\right]$ and radical cation $\left[\rho_{s}{ }^{r c}(r)\right]$

$P_{k}{ }^{+}=\rho_{s}^{r a}(r)($ for nucleophilic attack) (5)

$P_{k}{ }^{-}=\rho_{s}{ }^{r c}(r)$ (for electrophilic attack) (6)

Solvent effects in toluene were studied using the polarizable continuum model (PCM) within the selfconsistent reaction field [48-50] (SCRF) framework. The thermodynamic parameters were calculated at $383 \mathrm{~K}$ and $1 \mathrm{~atm}$.

The topological analysis of the ELF $[32,33]$ and QTAIM $[34,35]$ was carried out using Multiwfn software [51] using high quality grid. The ELF localization domains were visualized using UCSF-Chimera software [52] and $\mathrm{NCl}$ gradient isosurfaces were visualized using VMD software [53]. All calculations were performed using Gaussian 16 suite of programs [54].

\section{Results And Discussion}

\subsection{Analysis of the CDFT indices}

The conceptual DFT [30, 31, 43] (CDFT) indices have been applied in the reactivity analysis of several Diels Alder and 32CA reactions [30] to predict the electronic character of the reacting counterparts and consequently the direction of electronic flux. Accordingly, the global CDFT indices, namely the electronic chemical potential $(\mu)[30,43]$, chemical hardness $[30,44](\eta)$, global electrophilicity $[30,45](\omega)$ and the nucleophilicity $[30,46](\mathrm{N})$ at the ground state (GS) of the reagents are given in Table 1. The standard 
CDFT reactivity scales are defined at B3LYP/6-31G(d) computational level $[45,46]$ and has therefore been used to characterize the reagents within the respective standard scales.

The electrophilicity $\omega$ index of the azido alkyne 10 is $1.51 \mathrm{eV}$ being classified as a strong electrophile within the electrophilicity scale [45] while its nucleophilicity $\mathrm{N}$ index is $2.12 \mathrm{eV}$ being classified as a moderate nucleophile within the nucleophilicity scale [46]. On the other hand, the azido alkynes 11 ( $\omega=$ $1.45 \mathrm{eV})$ and $12(\omega=1.49 \mathrm{eV})$ are classified as moderate electrophiles and moderate nucleophiles $(2.00<$ $\mathrm{N}<3.00 \mathrm{eV}$ ). Note that the electrophilicity $\omega$ index of the azido alkyne 10 is higher than that of 11 and 12 and the nucleophilicity $\mathrm{N}$ index of azido alkyne 10 is lower than that of $\mathbf{1 1}$ and $\mathbf{1 2}$ owing to the terminal alkynyl substitution. The decreased propensity of 10 to share electronic charge is also evident from the slightly lower electronic chemical potential $\mu$ value $(\mu=-4.15 \mathrm{eV})$ relative to $11(\mu=-3.73 \mathrm{eV})$ and $12(\mu=$ $-4.01 \mathrm{eV})$.

Table 1. B3LYP/6-31G(d) calculated electronic chemical potential $\mu$, chemical hardness $\eta$, global electrophilicity $\omega$ and global nucleophilicity $N$, in eV, of the reagents

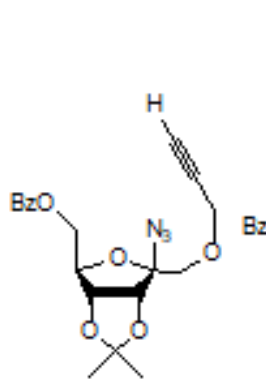

10

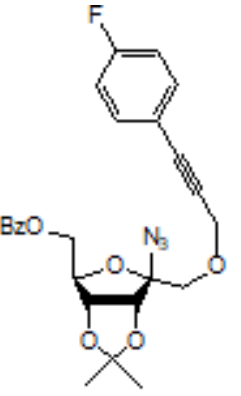

11

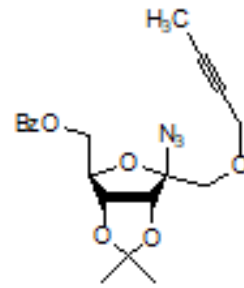

12

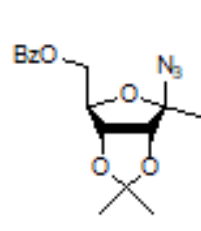

20

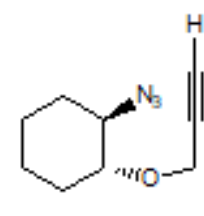

16

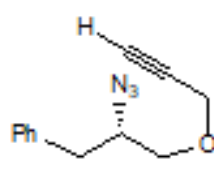

18

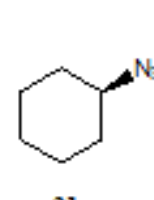

21

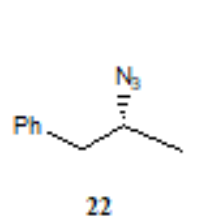

22

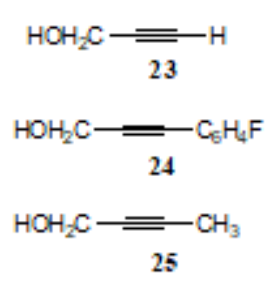

\begin{tabular}{ccccc}
\hline & $\mu$ & $\eta$ & $\omega$ & $N$ \\
\hline $\mathbf{1 0}$ & -4.15 & 5.69 & 1.51 & 2.12 \\
$\mathbf{1 1}$ & -3.73 & 4.79 & 1.45 & 2.99 \\
$\mathbf{1 2}$ & -4.01 & 5.41 & 1.49 & 2.39 \\
$\mathbf{1 6}$ & -3.65 & 5.82 & 1.14 & 2.56 \\
$\mathbf{1 8}$ & -3.54 & 5.88 & 1.06 & 2.64 \\
$\mathbf{2 0}$ & -4.11 & 5.50 & 1.54 & 2.26 \\
$\mathbf{2 1}$ & -3.66 & 6.12 & 1.09 & 2.39 \\
$\mathbf{2 2}$ & -3.61 & 5.9 & 1.10 & 2.56 \\
$\mathbf{2 3}$ & -3.28 & 7.97 & 0.67 & 1.85 \\
$\mathbf{2 4}$ & -3.58 & 5.31 & 1.21 & 2.88 \\
$\mathbf{2 5}$ & -3.18 & 8.11 & 0.62 & 1.88 \\
\hline
\end{tabular}


The electrophilicity $\omega$ index of the azido alkynes 16 and 18 are $1.14 \mathrm{eV}$ and $1.06 \mathrm{eV}$ respectively, being classified as the moderate electrophiles, and the nucleophilicity index are $2.56 \mathrm{eV}$ and $2.64 \mathrm{eV}$, being classified as the moderate nucleophiles. The electronic chemical potential $\mu$ of 16 and 18 are $-3.65 \mathrm{eV}$ and $-3.54 \mathrm{eV}$, suggesting higher tendency to share electronic charge compared to the azido alkynes 10, 11 and 12. The electronic chemical potential $\mu$ of the azide $\mathbf{2 0}(\mu=-4.11 \mathrm{eV})$ is lower than that of the alkynes $23(\mu=-3.28 \mathrm{eV}), 24(\mu=-3.58 \mathrm{eV})$ and $25(\mu=3.18 \mathrm{eV})$, suggesting electronic flux from the alkynes 23-25 to the azide 20 , the latter being classified as a strong electrophile $(\omega=1.54 \mathrm{eV})$. The electronic chemical potential $\mu$ of the azides $21(\mu=-3.66 \mathrm{eV})$ and $22(\mu=-3.61 \mathrm{eV})$ are comparable to that of the alkynes 2325. The electrophilicity $\omega$ index of the alkynes 23 and 25 are $0.67 \mathrm{eV}$ and $0.62 \mathrm{eV}$ being classified as the marginal electrophiles, while alkyne $\mathbf{2 4}$ with electrophilicity $\omega$ index of $1.21 \mathrm{eV}$ is classified as the moderate electrophile.

When the non-symmetric electrophilic-nucleophilic pair approach each other, the most feasible two-center interaction takes place between the most nucleophilic center of the nucleophile and the most electrophilic center of the electrophile. Domingo [47] proposed the electrophilic $\mathrm{P}_{\mathrm{k}}{ }^{+}$Parr functions and the nucleophilic $\mathrm{P}_{\mathrm{k}}{ }^{-}$Parr functions derived from the Mulliken atomic spin densities (MASDs) to predict the local reactivity at the reacting counterparts. Accordingly, the MASDs of the radical anion and the radical cation of the azido alkyne 10 along with the nucleophilic $\mathrm{P}_{\mathrm{k}}{ }^{-}$Parr functions at the alkyne moiety and the electrophilic $\mathrm{P}_{\mathrm{k}}{ }^{+}$Parr functions at the azide are represented in Figure 1. Note that $\mathrm{C} 4\left(\mathrm{P}_{\mathrm{k}}{ }^{-}=0.052\right)$ of the alkyne moiety is the more nucleophilic center than C5 $\left(\mathrm{P}_{\mathrm{k}}{ }^{-}=0.026\right)$, while N3 $\left(\mathrm{P}_{\mathrm{k}}{ }^{+}=0.071\right)$ is the more electrophilic center than $\mathrm{N} 1\left(\mathrm{P}_{\mathrm{k}}{ }^{+}=-0.007\right)$, thus predicting a feasible two center interaction between N3 and $\mathrm{C} 4$ along the intramolecular 32CA reaction. Note that $\mathrm{C} 4$ and $\mathrm{C} 5$ of the alkyne moiety are not electrophilic and the radical anion does not show any MASD isosurface at the alkyne moiety (Figure 1).

3.2. Analysis of the ELF topology of the reagents

The topological analysis of the ELF allows understanding the electronic structure and characterizes the bonding and non-bonding regions in a molecule. The ELF valence basin populations at the GS of the reagents are given in Table 2 while the ELF localization domains are represented in Figure 2. The ELF of the azido alkynes 10, 11, 12, 16 and 18 show the presence of $\mathrm{V}(\mathrm{N} 1)$ and $\mathrm{V}(\mathrm{N} 3)$ monosynaptic basins integrating 3.47-3.52 e and 3.74-3.79 e respectively associated with the non-bonding electron density at $\mathrm{N} 1$ and N3 nitrogen. The $\mathrm{V}(\mathrm{N} 1, \mathrm{~N} 2)$ disynaptic basin integrates 2.53-2.58 e associated with the N1-N2 bonding region, while the $\mathrm{V}(\mathrm{N} 2, \mathrm{~N} 3)$ and $\mathrm{V}^{\prime}(\mathrm{N} 2, \mathrm{~N} 3)$ disynaptic basins integrating a total population of 4.084.13 e are associated with the N2-N3 bonding region. The $\mathrm{C} 4-\mathrm{C} 5$ alkyne bonding region integrates at the total population of 5.36-5.51 e. The ELF topological study allows correlating the molecular reactivity with the electronic structure of a three atom component (TAC) participating in the 32CA reaction, following the standard classification of the TACs, namely the pseudodiradical, pseudo(mono)radical, carbenoid and zwitter-ionic TACs [15-16, 24]. The presence of a monosynaptic basin integrating less than $1 \mathrm{e}$ is associated with the presence of a pseudoradical center, while that integrating less than $2 \mathrm{e}$ with the carbenoid centre. TACs with two pseudoradical centers are denoted as the pseudodiradical ones and exhibit very high reactivity and consequently lowest activation energy barrier. On the other hand, the TACs 
with one pseudoradical center are the pseudo(mono)radical ones and show comparable reactivity as the carbenoid TACs, the latter being associated with the presence of a carbenoid center. The zwitter-ionic TACs show the least reactivity (high activation energy barrier) and do not show the presence of pseudoradical or carbenoid centers [24].

The absence of any pseudoradical or carbenoid center in the azide moiety of the azido alkynes $10,11,12$, 16 and 18 classifies its zwitter-ionic TAC character associated with the high activation energy (See Section 3.3.) demanding appropriate electrophilic-nucleophilic interactions. The proposed Lewis like structures on the basis of ELF valence basin populations and the natural atomic charges are given in Scheme 4. Note that C4 of the azido alkynes 10,16 and 18 are negatively charged by -0.24 e, -0.22 e and -0.23 e, while that of the alkynyl azides 11 and 12 show minimal negative charges of -0.03 e and -0.07 e owing to the terminal alkynyl substitution. In the azide moiety, N1 nitrogen is negatively charged by -0.39 e to -0.43 e, while N3 shows minimal negative charge of -0.06 e to -0.09 e, thus provoking a polarization of charge distribution along the N1-N2-N3 bonding region.

Table 2

ELF valence basin populations at the MPWB1K/6$311 \mathrm{G}(\mathrm{d}, \mathrm{p})$ optimized azido alkynes associated with the intramolecular 32CA reaction

\begin{tabular}{|llllll|}
\hline & 10 & 11 & 12 & 16 & 18 \\
\hline $\mathrm{V}(\mathrm{N} 1)$ & 3.49 & 3.49 & 3.47 & 3.49 & 3.52 \\
\hline $\mathrm{V}(\mathrm{N} 1, \mathrm{~N} 2)$ & 2.55 & 2.53 & 2.56 & 2.58 & 2.53 \\
\hline $\mathrm{V}(\mathrm{N} 2, \mathrm{~N} 3)$ & 2.38 & 2.39 & 2.36 & 2.31 & 2.28 \\
\hline $\mathrm{V}(\mathrm{N} 2, \mathrm{~N} 3)$ & 1.74 & 1.73 & 1.75 & 1.77 & 1.85 \\
\hline $\mathrm{V}(\mathrm{N} 3)$ & 3.75 & 3.75 & 3.76 & 3.79 & 3.74 \\
\hline $\mathrm{V}(\mathrm{C} 4, \mathrm{C} 5)$ & 1.81 & 2.61 & 2.70 & 2.41 & 3.24 \\
\hline $\mathrm{V}(\mathrm{C} 4, \mathrm{C} 5)$ & 0.85 & 2.81 & 2.71 & 0.10 & 2.12 \\
\hline $\mathrm{V}^{\prime \prime}(\mathrm{C} 4, \mathrm{C} 5)$ & 2.70 & & 0.10 & 0.36 & \\
\hline $\mathrm{V}^{\prime \prime \prime}(\mathrm{C} 4, \mathrm{C} 5)$ & & & & 2.50 & \\
\hline
\end{tabular}

3.3. Study of the PES of the intramolecular 32CA reactions

The search for the stationary points along the potential energy surface (PES) of the intramolecular reactions allowed locating the azido alkynes 10,11, 12, 16 and 18, the TSs TS1-TS5 and the triazolooxazines 13,14, 15, 17 and 19 (Scheme 5). These 32CA reactions follow one-step mechanism.

The total and relative energies of the reagents, TSs and the products are given in Table 3 and the thermodynamic parameters, namely the enthalpies, entropies and free energies in toluene at $110^{\circ} \mathrm{C}$ are 
given in Table 4. The studied energy profile allows arriving at some appealing conclusions (1) The 32CA reactions show negative reaction free energies between -67.8 to $-71.6 \mathrm{kcal} \mathrm{mol}^{-1}$ in toluene, suggesting highly exergonic reactions under kinetic control and hence irreversible. (2) The activation energy of TS1 is lowered than that of TS2 and TS3 by $2.7 \mathrm{kcal} \mathrm{mol}^{-1}$ and $2.1 \mathrm{kcal} \mathrm{mol}^{-1}$ in gas phase and by 2.4 and 2.3 $\mathrm{kcal} \mathrm{mol}^{-1}$ in toluene. The activation enthalpy of TS1 is lowered than that of TS2 and TS3 by $2.3 \mathrm{kcal}$ $\mathrm{mol}^{-1}$ and $2.4 \mathrm{kcal} \mathrm{mol}^{-1}$. Note that the activation enthalpies of TS4 and TS5 are increased by $2.7 \mathrm{kcal}$ $\mathrm{mol}^{-1}$ and $1.5 \mathrm{kcal} \mathrm{mol}^{-1}$ relative to TS1. The intramolecular 32CA reaction of azido alkyne 10 is the most energetically feasible one, as expected from the lowest electronic chemical potential $\mu=-4.11 \mathrm{eV}$ of azide 20 along the series (Table 1).

Table 3

MPWB1K/6-311G $(\mathrm{d}, \mathrm{p})$ total $(\mathrm{E}$, in a.u.) and relative $\Delta \mathrm{E}$ (in $\mathrm{kcal} \mathrm{mol}^{-1}$ ) energies of the stationary points associated with the intramolecular 32CA reactions in gas phase and in toluene

\begin{tabular}{|lllll|}
\hline \multicolumn{4}{|l}{ Gas phase } & \multicolumn{3}{ll}{ Toluene } \\
\hline & $\mathrm{E}$ & $\Delta \mathrm{E}$ & $\mathrm{E}$ & $\Delta \mathrm{E}$ \\
\hline 10 & -1351.801970 & & -1351.808819 & \\
\hline TS1 & -1351.768035 & 21.3 & -1351.774480 & 21.5 \\
\hline 13 & -1351.925033 & -77.2 & -1351.933014 & -77.9 \\
\hline 11 & -1682.041191 & & -1682.048568 & \\
\hline TS2 & -1682.002995 & 24.0 & -1682.010449 & 23.9 \\
\hline 14 & -1682.161642 & -75.6 & -1682.169768 & -76.1 \\
\hline 12 & -1391.112407 & & -1391.119012 & \\
\hline TS3 & -1391.075136 & 23.4 & -1391.081117 & 23.8 \\
\hline 15 & -1391.232286 & -75.2 & -1391.239513 & -75.6 \\
\hline 16 & -589.947920 & & -589.951031 & \\
\hline TS4 & -589.911032 & 23.1 & -589.912641 & 24.1 \\
\hline 17 & -590.069070 & -76.0 & -590.074551 & -77.5 \\
\hline 18 & -704.231309 & & -704.235614 & \\
\hline TS5 & -704.195301 & 22.6 & -704.199307 & 22.8 \\
\hline 19 & -704.349489 & -74.2 & -704.355225 & -75.1 \\
\hline & & & & \\
\hline
\end{tabular}


(3) The thermodynamic corrections in toluene decrease the activation energies by $1-1.3 \mathrm{kcal} \mathrm{mol}^{-1}$ relative to the activation enthalpies, and the reaction energies by $1.8-2.7 \mathrm{kcal} \mathrm{mol}^{-1}$ relative to the reaction enthalpies. Note that these reactions show high activation enthalpies and Gibbs free energies (greater than $20 \mathrm{kcal} \mathrm{mol}^{-1}$ ) characteristic of the zwitter-ionic character of the azide moiety (Section 3.2.). (4) These unimolecular reactions show negative entropies of activation between -6.6 to $10.4 \mathrm{kcal} \mathrm{mol}^{-1}$ and negative entropies of reaction between -10.9 to $-15.3 \mathrm{kcal} \mathrm{mol}^{-1}$. The unfavorable entropies result in the increase of the activation free energies by $1.9-3.1 \mathrm{kcal} \mathrm{mol}^{-1}$ relative to the activation enthalpies and the reaction free energies by $3.2-5.9 \mathrm{kcal} \mathrm{mol}^{-1}$. Consequently, the activation free energies of these 32CA reactions are between 23.4 to $26.7 \mathrm{kcal} \mathrm{mol}^{-1}$

Table 4

MPWB1K/6-311G $(\mathrm{d}, \mathrm{p})$ enthalpies $\left(\mathrm{H}\right.$, in a.u.), entropies (S, in Cal mol ${ }^{-1} \mathrm{~K}^{-1}$ ) and Gibbs free energies ( $G$, in a.u.), and relative enthalpies $\left(\Delta \mathrm{H}\right.$, in $\left.\mathrm{kcal} \mathrm{mol}^{-1}\right)$, entropies $\left(\Delta S\right.$, in Cal mol $\left.{ }^{-1} \mathrm{~K}^{-1}\right)$ and Gibbs free energies $\left(\Delta \mathrm{G}\right.$, in kcal mol$\left.{ }^{-1}\right)$, computed at $110^{\circ} \mathrm{C}$ and $1 \mathrm{~atm}$ in toluene, for the stationary points associated with the intramolecular 32CA reactions

\begin{tabular}{|lllllll|}
\hline & H & $\Delta H$ & S & $\Delta S$ & G & $\Delta G$ \\
\hline 10 & -1351.369900 & & 204.754 & & -1351.494920 & \\
\hline TS1 & -1351.337485 & 20.3 & 196.772 & -8.0 & -1351.457631 & 23.4 \\
\hline 13 & -1351.490374 & -75.6 & 191.622 & -13.1 & -1351.607376 & -70.6 \\
\hline 11 & -1681.525367 & & 239.815 & & -1681.671795 & \\
\hline TS2 & -1681.489311 & 22.6 & 233.181 & -6.6 & -1681.631689 & 25.2 \\
\hline 14 & -1681.643764 & -74.3 & 224.921 & -14.9 & -1681.781098 & -68.6 \\
\hline 12 & -1390.648597 & & 216.783 & & -1390.780962 & \\
\hline TS3 & -1390.612434 & 22.7 & 206.417 & -10.4 & -1390.73847 & 26.7 \\
\hline 15 & -1390.766055 & -73.7 & 201.488 & -15.3 & -1390.889081 & -67.8 \\
\hline 16 & -589.716008 & & 108.446 & & -589.767534 & \\
\hline TS4 & -589.679406 & 23.0 & 101.896 & -6.6 & -589.727821 & 24.9 \\
\hline 17 & -589.835264 & -74.8 & 97.509 & -10.9 & -589.881593 & -71.6 \\
\hline 18 & -703.982059 & & 126.183 & & -704.042013 & \\
\hline TS5 & -703.947262 & 21.8 & 117.942 & -8.2 & -704.0033 & 24.3 \\
\hline 19 & -704.096983 & -72.1 & 113.266 & -12.9 & -704.150799 & -68.3 \\
\hline
\end{tabular}


The MPWB1K/6-311G(d,p) optimized gas phase geometries of the TSs associated with the 32CA reactions are displayed in Figure 3. The lengths of the N1-C5 and N3-C4 forming bonds are 2.124 and

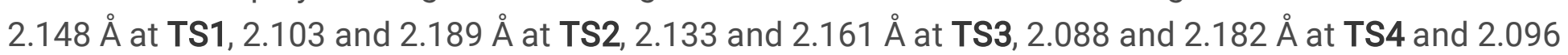
and 2.177 $\AA$ at TS5. (1) Considering that the C-N bond formation takes place at 1.8-1.9 $\AA$, it can be predicted that the formation of new N1-C5 and N3-C4 single bonds has not been started at the TSs, in conformity with the ELF study at the TSs (see Section 3.4). (2) The difference in the forming bond distances $\Delta \mathrm{d}$ are $0.024,0.086,0.028,0.094$ and 0.081 respectively at TS1, TS2, TS3, TS4 and TS5, suggesting minimal asynchronicity. Note that the N1-C5 forming bond distance is shorter than the N3-C4 one, in agreement with the earlier N1-C5 bond formation along the reaction pathway predicted from the bonding evolution theory study (see Section 3.5) (3) Inclusion of solvent effects in toluene causes unappreciable changes in the forming bond distances at the TSs.

\subsection{Topological analysis of the ELF at the TSs and along the reaction path associated with the intramolecular reaction}

The most significant ELF valence basin populations at the TSs are given in Table 5, while the ELF localization domains of TS1, TS4 and TS5 are shown in Figure 4. The ELF at the TSs show the presence of $\mathrm{V}(\mathrm{N} 1)$ and $\mathrm{V}(\mathrm{N} 3)$ monosynaptic basins integrating the total population of $3.36-3.40$ e and $3.69-3.72$ e associated with the non-bonding electron density on the N1 and N3 nitrogen. Note that the V(N1) and $\mathrm{V}(\mathrm{N} 3)$ monosynaptic basins are depopulated by $0.09-0.16$ e and $0.04-0.06 \mathrm{e}$ at the TSs relative to the azido alkynes. The N1-N2 and N2-N3 bonding regions are respectively depopulated by $0.67-0.72$ e and $1.17-1.19$ e at the TSs relative to the reagents to create the $V(N 2)$ monosynaptic basin associated with the non-bonding electron density at N2 nitrogen (integrating 2.00-2.03 e at the TSs). The C4-C5 bonding region integrates the total population of $5.04-5.31$ e at the TSs, indicating the depopulation of $0.15-0.38$ e relative to the azido alkynes. The absence of $\mathrm{V}(\mathrm{N} 1, \mathrm{C} 5)$ and $\mathrm{V}(\mathrm{N} 3, \mathrm{C} 4)$ disynaptic basins indicates that the formation of new N1-C5 and N3-C4 bonds has not been started at the TSs, in agreement with the forming bond distances (Figure 3). 
Table 5

ELF valence basin populations at the MPWB1K/6-

$311 \mathrm{G}(\mathrm{d}, \mathrm{p})$ optimized TSs associated with the intramolecular 32CA reaction

\begin{tabular}{|llllll|}
\hline & TS1 & TS2 & TS3 & TS4 & TS5 \\
\hline $\mathrm{V}(\mathrm{N} 1)$ & 3.40 & 3.39 & 3.40 & 3.36 & 3.36 \\
\hline $\mathrm{V}(\mathrm{N} 1, \mathrm{~N} 2)$ & 1.84 & 1.84 & 1.84 & 1.87 & 1.86 \\
\hline $\mathrm{V}(\mathrm{N} 2, \mathrm{~N} 3)$ & 2.94 & 2.95 & 2.93 & 2.91 & 2.94 \\
\hline $\mathrm{V}(\mathrm{N} 2)$ & 2.02 & 2.00 & 2.03 & 2.02 & 2.01 \\
\hline $\mathrm{V}(\mathrm{N} 3)$ & 3.69 & 3.69 & 3.72 & 3.71 & 3.70 \\
\hline $\mathrm{V}(\mathrm{C} 4, \mathrm{C} 5)$ & 2.51 & 2.44 & 2.55 & 2.52 & 2.51 \\
\hline $\mathrm{V}(\mathrm{C} 4, \mathrm{C} 5)$ & 2.67 & 2.60 & 2.76 & 2.70 & 2.70 \\
\hline
\end{tabular}

In order to study the bonding changes along the intramolecular reaction and to establish the molecular mechanism, the topological analysis of the ELF along the 32CA reaction of the azido alkyne 10 has been carried out. The molecular mechanism represented by the Lewis-like structures derived from the ELF topology is shown in Scheme 6. The most significant valence basin populations of the selected IRC structures defining the ELF topological phases are given in Table 6, while the basin attractor positions of the relevant ELF structures associated with the formation of N1-C5 and N3-C4 bonds are shown in Figure 5 .

The conjunction of ELF study [32,33] and Thom's catastrophe theory [55], namely the bonding evolution theory (BET) study proposed by Krokoidis [56] allows structuring the molecular mechanism. This 32CA reaction takes place along 8 ELF topological phases. Phase / begins at the azido alkyne SO, which corresponds with the starting point of the IRC. Phase // is characterized by the creation of a new V(N2) monosynaptic basin with an initial population of $0.52 \mathrm{e}$ associated with the formation of non-bonding electron density at $\mathbf{S 1}$. Note that the $\mathrm{V}(\mathrm{N} 1, \mathrm{~N} 2)$ disynaptic basin is depopulated from $2.55 \mathrm{e}$ at $\mathbf{S} 0$ to $2.37 \mathrm{e}$ at $\mathbf{S} 1$, while the two $\mathrm{V}(\mathrm{N} 2, \mathrm{~N} 3)$ and $\mathrm{V}^{\prime}(\mathrm{N} 2, \mathrm{~N} 3)$ disynaptic basins integrating the total population of $4.12 \mathrm{e}$ at S0 are merged into one V(N2,N3) disynaptic basin integrating 3.83 e at S1. The energy cost (EC) associated with these bonding changes is $10.5 \mathrm{kcal} \mathrm{mol}^{-1}$. Phase II/ begins at structure $\mathbf{S} 2(\mathrm{~d}(\mathrm{~N} 3-\mathrm{C} 4)=$ $2.10 \AA, d(N 1-C 5)=2.08 \AA)$ and is characterized by the creation of a new $V(C 4)$ monosynaptic basin, with an initial population of 0.26 e (see Figure 5), which derives electron density from the C4-C5 bonding region, which experiences depopulation from 5.35 e at $\mathbf{S 1}$ to 4.90 e at $\mathbf{S 2}$. Phase IV begins at structure S3 $(\mathrm{d}(\mathrm{N} 3-\mathrm{C} 4)=2.01 \AA, \mathrm{d}(\mathrm{N} 1-\mathrm{C} 5)=2.00 \AA)$ and is characterized by the creation of a new V(C5) monosynaptic basin, with an initial population of 0.11 e (see Figure 5 ). Note that the $\mathrm{C} 4-\mathrm{C} 5$ bonding region is depopulated from 4.90 e at S2 to 4.59 e at S3. Phase $V$ begins at structure S4 (d(N3-C4) $=1.95 \AA$, d(N1C5) $=1.95 \AA$ ). In this phase, the non-bonding electron density at N1 nitrogen is split into two monosynaptic basins V(N1) (2.29 e) and V'(N1) (1.11 e), and subsequently in Phase VI, starting at S5 
$(\mathrm{d}(\mathrm{N} 3-\mathrm{C} 4)=1.90 \AA, \mathrm{d}(\mathrm{N} 1-\mathrm{C} 5)=1.91 \AA)$, the formation of first N1-C5 single bond takes place by the coupling of the pseudoradical centre at $\mathrm{C} 5$ and part of the non-bonding electron density of the N1 nitrogen. Phase VII begins at structure S6 $(\mathrm{d}(\mathrm{N} 3-\mathrm{C} 4)=1.89 \AA \mathrm{d}(\mathrm{N} 1-\mathrm{C} 5)=1.90 \AA$ ). In this phase, the nonbonding electron density at N3 nitrogen is split into two monosynaptic basins V(N3) (3.78 e) and $\mathrm{V}^{\prime}(\mathrm{N} 3)$ (0.40 e), and subsequently in Phase VII, starting at S7 (d(N3-C4) $=1.74 \AA$, d(N1-C5) $=1.76 \AA)$, the formation of second N3-C4 single bond takes place by the coupling of the pseudoradical centre at C4 and part of the non-bonding electron density of the N3 nitrogen. From S7 to the product 13, the molecular geometry is relaxed by $66.8 \mathrm{kcal} \mathrm{mol}^{-1}$.

This BET study allows arriving at some noteworthy conclusions (1) the activation energy of $21.3 \mathrm{kcal}$ $\mathrm{mol}^{-1}$ associated with the intramolecular 32CA reaction can be mainly related with the continuous depopulation of the N1-N2, N2-N3 and the C4-C5 bonding regions, demanded for the creation of the nonbonding electron density at the N2 nitrogen and the pseudoradical centre at the C4 carbon (2) The pseudoradical centre at C4 carbon is created in Phase III earlier to that at C5 carbon created in Phase IV along the reaction path, which is consistent with the most nucleophilic center at $\mathrm{C} 4$ carbon of the alkyne moiety as anticipated by the Parr function analysis (Figure 1). However, the N1-C5 bond formation takes place is formed earlier along the reaction path due to the energetically feasible formation of the six membered spirocyclic ring resulting from the earlier N1-C5 bond formation, compared to the formation of the nine membered spirocyclic ring resulting from the earlier N3-C4 bond formation. (3) The formation of second N3-C4 bond takes place when the first N1-C5 bond formation is completed by $59 \%$, suggesting asynchronicity in the bond formation process, although not to a considerable extent, consistent with the minimal difference in the N1-C5 and N3-C4 forming bond distances (Figure 3). 
ELF valence basin populations, distances of the forming bonds, and relative electronic energies of the IRC structures $\mathbf{S O}$ - S7 defining the eight phases characterizing the molecular mechanism of the intramolecular 32CA reaction of 10 . Distances are given in angstroms, $\AA$, and relative energies in $\mathrm{kcal} \cdot \mathrm{mol}^{-1}$.

\begin{tabular}{|c|c|c|c|c|c|c|c|c|c|}
\hline Phases & I & II & III & $I V$ & $V$ & $V I$ & VII & VIII & \\
\hline Structures & so & s1 & S2 & S3 & s4 & S5 & S6 & s7 & 13 \\
\hline d(N3-C4) & 3.027 & 2.538 & 2.097 & 2.008 & 1.949 & 1.904 & 1.889 & 1.743 & 1.347 \\
\hline $\mathrm{d}(\mathrm{N} 1-\mathrm{C} 5)$ & 3.326 & 2.447 & 2.080 & 2.003 & 1.950 & 1.910 & 1.896 & 1.761 & 1.341 \\
\hline$\Delta \mathrm{E}$ & 0.0 & 10.5 & 21.0 & 17.9 & 14.1 & 10.2 & 8.7 & -10.4 & -77.2 \\
\hline $\mathrm{V}(\mathrm{N} 1)$ & 3.49 & 3.38 & 3.40 & 3.40 & 2.29 & 2.21 & 2.19 & 2.03 & 0.76 \\
\hline $\mathrm{V}(\mathrm{N} 1, \mathrm{~N} 2)$ & 2.55 & 2.37 & 1.82 & 1.78 & 1.77 & 1.76 & 1.76 & 1.76 & 1.76 \\
\hline $\mathrm{V}(\mathrm{N} 2, \mathrm{~N} 3)$ & 2.38 & 3.83 & 2.88 & 2.78 & 2.72 & 2.68 & 2.67 & 2.54 & 2.05 \\
\hline $\mathrm{V}^{\prime}(\mathrm{N} 2, \mathrm{~N} 3)$ & 1.74 & & & & & & & & \\
\hline V(N3) & 3.75 & 3.71 & 3.70 & 3.73 & 3.75 & 3.78 & 3.78 & 3.17 & 3.15 \\
\hline$V(C 4, C 5)$ & 1.81 & 3.71 & 2.45 & 2.32 & 2.22 & 2.14 & 2.13 & 2.01 & 3.42 \\
\hline$V^{\prime}(C 4, C 5)$ & 0.85 & 1.49 & 2.45 & 2.27 & 2.19 & 2.15 & 2.14 & 2.02 & \\
\hline$V^{\prime \prime}(C 4, C 5)$ & 2.70 & 0.15 & & & & & & & \\
\hline $\mathrm{V}(\mathrm{N} 2)$ & & 0.52 & 2.13 & 2.29 & 2.38 & 2.45 & 2.47 & 2.63 & 2.87 \\
\hline $\mathrm{V}(\mathrm{C} 4)$ & & & 0.26 & 0.49 & 0.58 & 0.64 & 0.65 & & \\
\hline V(C5) & & & & 0.11 & 0.20 & & & & \\
\hline $\mathrm{V}^{\prime}(\mathrm{N} 1)$ & & & & & 1.11 & & & & \\
\hline $\mathrm{V}(\mathrm{N} 1, \mathrm{C} 5)$ & & & & & & 1.43 & 1.45 & 1.70 & 2.89 \\
\hline$V^{\prime}(\mathrm{N} 3)$ & & & & & & & 0.40 & & \\
\hline$V(N 3, C 4)$ & & & & & & & & 1.42 & 2.26 \\
\hline
\end{tabular}

Topological analysis of the AIM at the TSs involved in the 32CA reactions

The covalent and non-covalent interactions between the atomic pairs connected by a bond path can be characterized from the electron density accumulation and the Laplacian of electron density at the bond critical points (BCPs) proposed by Bader and Coworkers [34, 35]. The BCPs, CP1 and CP2 are associated with the forming N3-C4 and N1-C5 bonds at the TSs. The total electron density, $\rho$ (a.u.), and the Laplacian 
of electron density (a.u.) at $\mathbf{C P 1}$ and $\mathbf{C P 2}$ are given in Table 7. The total electron density accumulation at CP2 is higher than that at CP1, consistent with the earlier N1-C5 bond formation along the reaction path (see Section 3.4). The positive Laplacian of electron density at the BCPs indicate non-covalent interaction $(\mathrm{NCl})$ at the TSs, which is in conformity with the absence of $\mathrm{V}(\mathrm{N} 1, \mathrm{C} 5)$ and $\mathrm{V}(\mathrm{N} 3, \mathrm{C} 4)$ disynaptic basins predicted from the ELF study (see Section 3.4).

Table 7

Total electron density, $\rho$ (a.u.), Laplacian of electron density (a.u.) of CP1 and CP2 at the TSs associated with the intramolecular 32CA reactions in gas phase and in toluene

\begin{tabular}{|cllll|}
\hline \multirow{4}{*}{} & \multicolumn{2}{l}{ CP1 (N3-C4) } & \multicolumn{2}{l|}{ CP2 (N1-C5) } \\
\cline { 2 - 5 } & $\rho$ & & $\rho$ & \\
\hline TS1 & 0.058 & 0.100 & 0.062 & 0.105 \\
\hline TS2 & 0.054 & 0.096 & 0.065 & 0.104 \\
\hline TS3 & 0.057 & 0.097 & 0.061 & 0.104 \\
\hline TS4 & 0.054 & 0.097 & 0.067 & 0.106 \\
\hline TS5 & 0.055 & 0.098 & 0.066 & 0.105 \\
\hline
\end{tabular}

The decomposition of the Laplacian of electron density into three Eigen values $\lambda_{1}, \lambda_{2}$ and $\lambda_{3}$ of the electron density Hessian matrix allows identifying the $\mathrm{NCls}$ by the sign of $\lambda_{2}$. The $\mathrm{NCl}$ gradient isosurfaces at TS1, TS4 and TS5 are shown in Figure 6. The forming N3-C4 and N1-C5 bonding regions show the same pattern at the isosurfaces with both blue and red surfaces in each case respectively characterizing the strong attractive $\mathrm{NCls}$ and strong repulsive NCls.

\section{Conclusion}

The intramolecular 32CA reactions of azido alkynes resulting in spirocyclic, tricyclic and bicyclic triazolooxazines have been studied within the molecular electron density theory perspective at MPWB1K/6-311G(d,p) level of theory. Analysis of the CDFT indices predicts the nucleophilic character of the alkyne moiety, while the azide counterpart is predicted as the electrophilic one. The Parr function analysis predicts the terminal alkyne carbon $\mathrm{C} 4$ as the most nucleophilic center, while the terminal nitrogen N3 is predicted as the most electrophilic center. The bonding evolution theory study predicts earlier formation of the pseudoradica/ center at C4 consistent with the Parr function analysis, but the N1$\mathrm{C} 5$ bond formation takes place earlier along the reaction path, suggesting energetic feasibility for the formation of six membered spirocyclic ring which outweighs the two center interaction between the most electrophilic and most nucleophilic centers. These kinetically controlled 32CA reactions follow one-step mechanism with high activation enthalpies in toluene from 20.3 to $23.0 \mathrm{kcal} \mathrm{mol}^{-1}$, while the activation 
free energies range from 23.4 to $26.7 \mathrm{kcal} \mathrm{mol}^{-1}$ due to the inclusion of unfavourable entropies of activation. The located early TSs do not show the formation of new N1-C5 and N3-C4 bonds, as evident from the geometrical parameters and the topological analysis of the ELF and the AIM. The activation energy is mainly associated with the formation of non-bonding electron density at N2 nitrogen and the pseudoradical centre at $\mathrm{C} 4$. The $\mathrm{NCl}$ gradient isosurfaces show strong attractive and strong repulsive non-covalent interactions at the interatomic bonding regions.

\section{Declarations}

\section{Funding:}

The authors declare that no funds, grants, or other support were received during the preparation of this manuscript.

\section{Conflicts of Interest/Competing Interests}

The authors have no relevant financial or non-financial interests to disclose. The authors declare no conflict of interest.

\section{Data Availability}

All datasets generated during and/or analysed during the current study are available from the corresponding author on reasonable request.

\section{Code Availability}

Not applicable

\section{Author Contributions}

All authors contributed to the study conception and design. Data collection and analysis were performed by Nivedita Acharjee, Haydar A Mohammad-Salim and Mrinmoy Chakraborty. The first draft of the manuscript was written by Nivedita Acharjee and all authors commented on previous versions of the manuscript. All authors read and approved the final manuscript.

\section{References}

1. Huisgen R (1984) In: Padwa A (ed) 1,3-Dipolar cycloaddition-Introduction, Survey, Mechanism. Wiley, New York

2. Huisgen R, Knorr R, Moebius L, Szeimies G (1965) 1.3-Dipolare Cycloadditionen, XXIII. Einige Beobachtungen zur Addition organischer Azide an CC-Dreifachbindungen. Chem Ber 98:4014-4021

https://doi.org/10.1002/cber.19650981228 
3. Krivopalov V P, Shkurko O P (2005) 1,2,3-Triazole and its derivatives. Development of methods for the formation of the triazole ring. Russian Chem Rev 74: 339-379

http://dx.doi.org/10.1070/RC2005v074n04ABEH000893

4. Arslan M, Acik G, Tasdelen M A (2019) The emerging applications of click chemistry reactions in the modification of industrial polymers. Polymer Chemistry 10: 3806-3821

https://doi.org/10.1039/C9PY00510B

5. Hein CD, Liu XM, Wang D (2008) Click Chemistry, A Powerful Tool for Pharmaceutical Sciences. Pharma Res 25: 2216-2230

https://doi.org/10.1007/s11095-008-9616-1

6. Rostovtsev VV, Green LG, Fokin VV, Sharpless KB (2002) Angew Chem Int Ed 41: 2596-2599

https://doi.org/10.1002/1521-3773(20020715)41:14\%3C2596::aid-anie2596\%3E3.0.co;2-4

7. Tornøe CW, Meldal M (2001) In: Lebl M, Houghten RA (eds) The Wave of the Future. American Peptide Society, San Diego

8. Tornøe CW, Christensen C, Meldal M (2002) Peptidotriazoles on Solid Phase: [1,2,3]-Triazoles by Regiospecific Copper(I)-Catalyzed 1,3-Dipolar Cycloadditions of Terminal Alkynes to Azides. J Org Chem 67: 3057-3064

https://doi.org/10.1021/jo011148j

9. Nebra N, García-Álvarez J (2020) Recent Progress of Cu-Catalyzed Azide-Alkyne Cycloaddition Reactions (CuAAC) in Sustainable Solvents: Glycerol, Deep Eutectic Solvents, and Aqueous Media. Molecules 25:2015

https://doi.org/10.3390/molecules25092015

10. Boren BC, Narayan S, Rasmussen LK, Zhang L, Zhao H, Lin Z, Jia G, Fokin VV (2008) RutheniumCatalyzed Azide-Alkyne Cycloaddition: Scope and Mechanism. J Am Chem Soc 130: 8923-8930

https://doi.org/10.1021/ja0749993

11. Li R, Jansen DJ, Dutta A (2009) Intramolecular azide-alkyne[3 + 2] cycloaddition: versatile route to new heterocyclic structural scaffolds. Org Biomol Chem 7:1921-1930

https://doi.org/10.1039/B818962E

12. Majumdar KC, Ray K, Ganai S (2010) Intramolecular Azide-Alkyne [3+2] Cycloaddition: A Versatile Route for the Synthesis of 1,2,3-Triazole Fused Dibenzo[1,5]diazocine Derivatives. Synthesis 12: 2101- 
https://doi.org/10.1055/s-0029-1218763

13. Mazur MO, Zhelavskyi OS, Zviagin EM, Shishkina SV, Musatov VI, Kolosov MA, Shvets EH, Andryushchenko AY, Chebanov VA (2021) Effective microwave-assisted approach to 1,2,3triazolobenzodiazepinones via tandem Ugi reaction/catalyst-free intramolecular azide-alkyne cycloaddition. Beilstein J Org Chem 17:678-687

https://doi.org/10.3762/bjoc.17.57

14. Cobb AJA, Dell'Isola A,Abdulsattar BO, McLachlan MMW,Neuman BW, Müller C, Shankland K, AlMulla HMN, Binks AWD, Elvidge W (2018) Synthesis and antiviral activity of novel spirocyclic nucleosides. New J Chem 42:18363-18380

https://doi.org/10.1039/C8NJ02777C

15. Domingo LR (2016), Molecular electron density theory: a modern view of reactivity in organic chemistry. Molecules 21:1319

https://doi.org/10.3390/molecules21101319

16. Ríos-Gutiérrez M, Domingo LR (2019) Unravelling the mysteries of the [3+2] cycloaddition reactions. Eur Jour Org Chem 2019: 267-282.

https://doi.org/10.1002/ejoc.201800916

17. Domingo LR, Acharjee N (2020) In Frontiers in Computational Chemistry, Ul-Haq Z, Wilson AK (ed(s)) Bentham and Science, Singapore, p. 174-227

https://doi.org/10.2174/9789811457791120050007

18. Domingo LR, Acharjee N (2020) Unravelling the Strain-Promoted [3+2] Cycloaddition Reactions of Phenyl Azide with Cycloalkynes from the Molecular Electron Density Theory Perspective. New J Chem 44:13633-13643

https://doi.org/10.1039/D0NJ02711A

19. Domingo LR, Acharjee N (2020) Unveiling the High Reactivity of Strained Dibenzocyclooctyne in [3+2] Cycloaddition Reactions with Diazoalkanes through the Molecular Electron Density Theory. J Phys Org Chem 33: e4100.

https://doi.org/10.1002/poc. 4100 
20. Domingo L R, Acharjee N (2021), Unveiling the Substituent Effects in the Stereochemistry of [3+2] Cycloaddition Reactions of Aryl- and Alkyldiazomethylphosphonates with Norbornadiene within a MEDT Perspective. ChemistrySelect 6: 10722-10733

https://doi.org/10.1002/slct.202102942

21. Domingo L R, Acharjee N (2018) [3+2] Cycloaddition reaction of C-phenyl-N-methyl nitrone to acyclic-olefin-bearing electron-donating substituent: a molecular electron density theory study. ChemistrySelect 3: 8373-8380.

https://doi.org/10.1002/slct.201801528

22. Domingo LR. Ríos-Gutiérrez M, Acharjee N (2019) A molecular electron density theory study of the chemoselectivity, regioselectivity, and diastereofacial selectivity in the synthesis of an anticancer spiroisoxazoline derived from a-santonin. Molecules 24:832

https://doi.org/10.3390/molecules24050832

23. Domingo L R, Acharjee N (2021), Unveiling the Chemo- and Regioselectivity of the [3+2] Cycloaddition Reaction between 4-Chlorobenzonitrile Oxide and $\beta$-Aminocinnamonitrile with a MEDT Perspective, ChemistrySelect, 6, 4521-4532

https://doi.org/10.1002/slct.202100978

24. Domingo LR, Ríos-Gutiérrez M, Pérez P (2018) A molecular electron density theory study of the reactivity and selectivities in [3+2] cycloaddition reactions of $\mathrm{C}, \mathrm{N}$-dialkyl nitrones with ethylene derivatives. J Org Chem 83: 2182-2197.

https://doi.org/10.1021/acs.joc.7b03093

25. Acharjee N, Salim HAM, Chakraborty M, Rao MP, Ganesh M (2021) Unveiling the high regioselectivity and stereoselectivity within the synthesis of spirooxindolenitropyrrolidine: A molecular electron density theory perspective, J Phys Org Chem 34: e4189

https://doi.org/10.1002/poc.4189

26. Domingo LR, M. Ríos-Gutiérrez M, Pérez P (2018) A Molecular Electron Density Theory Study of the Role of the Copper Metalation of Azomethine Ylides in [3 +2] Cycloaddition Reactions. J Org Chem 83: 10959-10973

https://doi.org/10.1021/acs.joc.8b01605

27. Ayouchia, HBEl, Lahoucine B, Anane H, Ríos-Gutiérrez M, Domingo LR, Stiriba SE (2018) Experimental and Theoretical MEDT Study of the Thermal [3+2] Cycloaddition Reactions of Aryl Azides with Alkyne Derivatives. ChemistrySelect 3: 1215-1233 
https://doi.org/10.1002/slct.201702588

28. Ayouchia, HBEl, Lahoucine B, Anane H, Domingo LR, Stiriba SE (2018) Understanding the mechanism and regioselectivity of the copper(I) catalyzed [3 +2$]$ cycloaddition reaction between azide and alkyne: a systematic DFT study. RSC Adv 8: 7670-7678

https://doi.org/10.1039/C7RA10653J

29. Domingo L R, Acharjee N (2020) A Molecular Electron Density Theory Study of the Grignard Reagent Mediated Regioselective Direct Synthesis of 1,5-disubstituted-1,2,3-Triazoles. J Phys Org Chem 33: e4062,

https://doi.org/10.1002/poc.4062

30. Domingo LR, Ríos-Gutiérrez M, Pérez $P$ (2016) Applications of the conceptual density functional theory indices to organic chemistry reactivity. Molecules 21:748

https://doi.org/10.3390/molecules21060748

31. Geerlings P, De Proft F, Langenaeker W (2003) Conceptual density functional theory. Chem Rev103:1793-1874

https://doi.org/10.1021/cr990029p

32. Becke AD, Edgecombe KE (1990) A simple measure of electron localization in atomic and molecular systems. J Chem Phys 92:5397-5403.

https://doi.org/10.1063/1.458517

33. Silvi B, Savin A (1994) Classification of chemical bonds based on topological analysis of electron localization functions. Nature 371: 683-686.

https://doi.org/10.1038/371683a0

34. Bader RFW (1994) Atoms in Molecules: A Quantum Theory. Clarendon Press, USA.

35. Bader RFW, Essén H (1984) The characterization of atomic interactions. J Chem Phys 80:19431960

https://doi.org/10.1063/1.446956

36. García JC, Johnson ER, Keinan S, Chaudret R, Piquemal JP, Beratan DN, Yang W (2011) NCIPLOT: A program for plotting noncovalent interaction regions. J Chem Theory Comput 7:625-632.

https://doi.org/10.1021/ct100641a

Page 19/26 
37. Schlegel HB (1982) Optimization of equilibrium geometries and transition structures. J Comput Chem 3: 214-218.

https://doi.org/10.1002/jcc.540030212

38. Zhao Y, Truhlar DG (2004) Hybrid Meta Density Functional Theory Methods for Thermochemistry, Thermochemical Kinetics, and Noncovalent Interactions: The MPW1B95 and MPWB1K Models and Comparative Assessments for Hydrogen Bonding and van der Waals Interactions. J Phys Chem A 108: 6908-6918.

https://doi.org/10.1021/jp048147q

39. Hehre WJ, Radom L, Schleyer PVR, Pople JA (1996) Ab initio Molecular Orbital Theory. Wiley, New York, USA.

40. Fukui K (1970) Formulation of the reaction coordinate. J Phys Chem 74: 4161-4163. https://doi.org/10.1021/j100717a029

41. González C, Schlegel HB (1990) Reaction path following in mass-weighted internal coordinates. J Phys Chem 94: 5523-5527.

https://doi.org/10.1021/j100377a021

42. González C, Schlegel HB (1991) Improved algorithms for reaction path following: Higher-order implicit algorithms. Chem Phys 95: 5853-5860.

https://doi.org/10.1063/1.461606

43. Parr RG, Yang W (1989) Density-functional theory of atoms and molecules. Oxford University Press, Oxford, 4:70-86.

44. Parr RG, Pearson, RG (1983) Absolute hardness: companion parameter to absolute electronegativity. J Am Chem Soc 105:7512-7516.

https://doi.org/10.1021/ja00364a005

45. Domingo LR, Aurell MJ, Pérez P, Contreras R (2002) Quantitative characterization of the global electrophilicity power of common diene/dienophile pairs in Diels-Alder reactions. Tetrahedron 58:44174423.

https://doi.org/10.1016/S0040-4020(02)00410-6

46. Domingo LR, Pérez P (2011) The nucleophilicity N index in organic chemistry. Org. Biomol Chem 9:7168-7175. 
47. Domingo LR, Pérez, P, Sáez JA (2013) Understanding the local reactivity in polar organic reactions through electrophilic and nucleophilic Parr functions. RSC Adv 3: 1486-1494. https://doi.org/10.1039/C2RA22886F

48. Tomasi J, Persico M (1994) Molecular Interactions in Solution: An Overview of Methods Based on Continuous Distributions of the Solvent. Chem Rev 94: 2027-2094. https://doi.org/10.1021/cr00031a013

49. Cances E, Mennucci B, Tomasi J (1997) A new integral equation formalism for the polarizable continuum model: Theoretical background and applications to isotropic and anisotropic dielectrics $\mathrm{J}$ Chem Phys 107: 3032-3041.

https://doi.org/10.1063/1.474659

50. Barone V, Cossi M, Tomasi J (1998) Geometry optimization of molecular structures in solution by the polarizable continuum model. J Comput Chem 19:404-417.

https://doi.org/10.1002/(SICI)1096-987X(199803)19:4<404::AID-JCC3>3.0.CO;2-W

51. Lu T, Chen F (2012) Multiwfn: A multifunctional wavefunction analyzer. J Comput Chem 33:580592.

https://doi.org/10.1002/jcc.22885

52. Pettersen EF, Goddard TD, Huang CC, Couch GS, Greenblatt DM, Meng EC, Ferrin TE (2004) UCSF Chimera-A visualization system for exploratory research and analysis. J Comput Chem 25:1605-1612 https://doi.org/10.1002/jcc.20084

53. Humphrey W, Dalke A, Schulten K (1996) VMD: Visual molecular dynamics. J Molec Graphics 14:3338.

https://doi.org/10.1016/0263-7855(96)00018-5

54. Frisch M, Trucks G, Schlegel H, Scuseria G, Robb M, Cheeseman J, Scalmani G, Barone V, Petersson G, Nakatsuji H, Gaussian 16.Revision A (2016), 3

55. Thom R (1972) StabilitéStructurelle et Morphogénèse. Intereditions, Paris.

56. Krokidis X, Noury S, Silvi B (1997) Characterization of elementary chemical processes by Catastrophe Theory. J Phys Chem A 101:7277-7282

https://doi.org/10.1021/jp9711508 


\section{Scheme}

Please see the Supplementary Files for the Scheme 1, 2, 3, 4, 5 and 6.

\section{Figures}
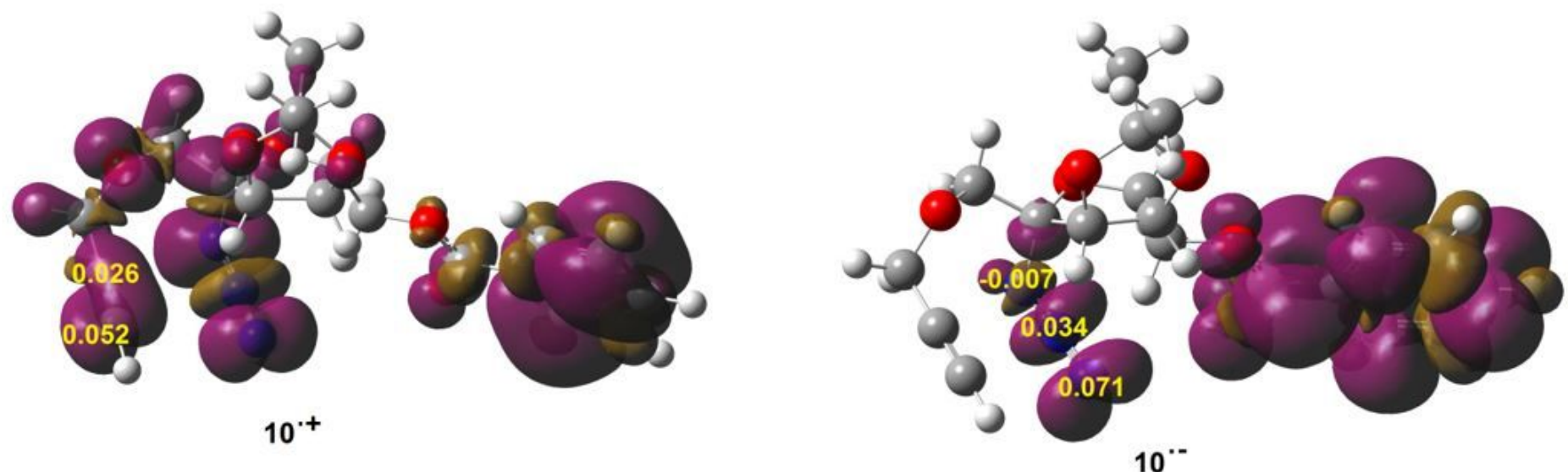

Figure 1

3D representations of the Mulliken atomic spin densities of the radical anion and radical cation of azido alkyne 10 together with the electrophilic Pk+ Parr functions of the azide moiety (N1-N2-N3) and the nucleophilic Pk-Parr functions of alkyne moiety (C4-C5).

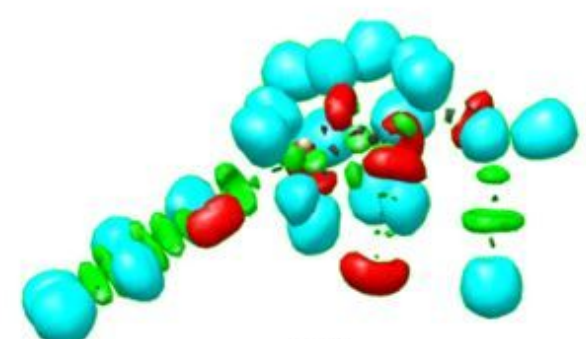

10

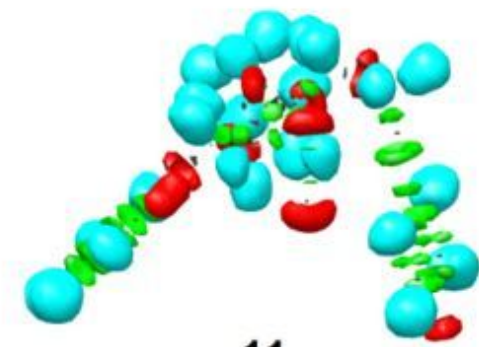

11

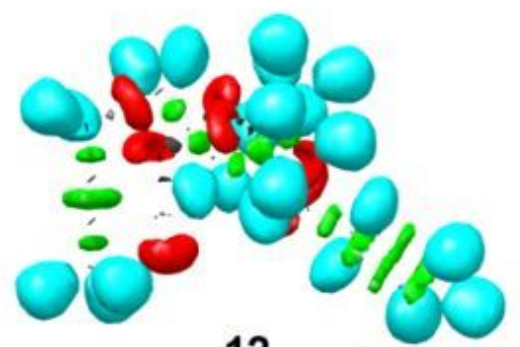

12

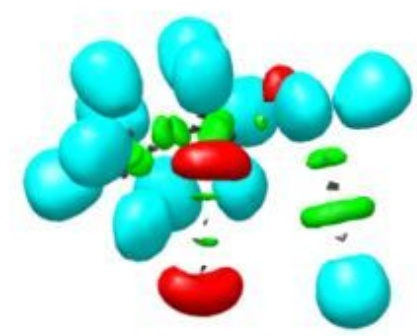

16

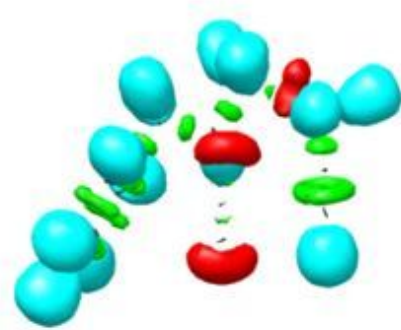

18

\section{Figure 2}

MPWB1K/6-311G(d,p) ELF localization domains and the most significant ELF valence basin populations (in average number of electrons e) of the azido alkynes. Protonated basins are shown in blue, 
monosynaptic basins in red, disynaptic basins in green and the core basins in black colour (Isovalue = $0.82)$.

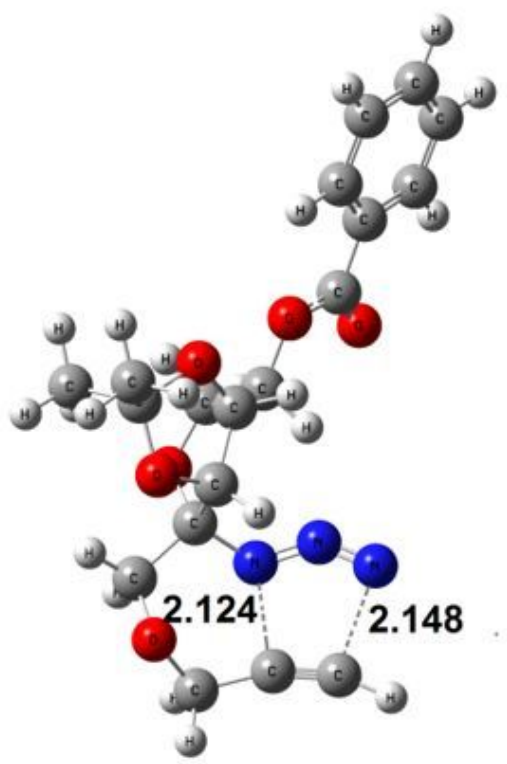

TS1

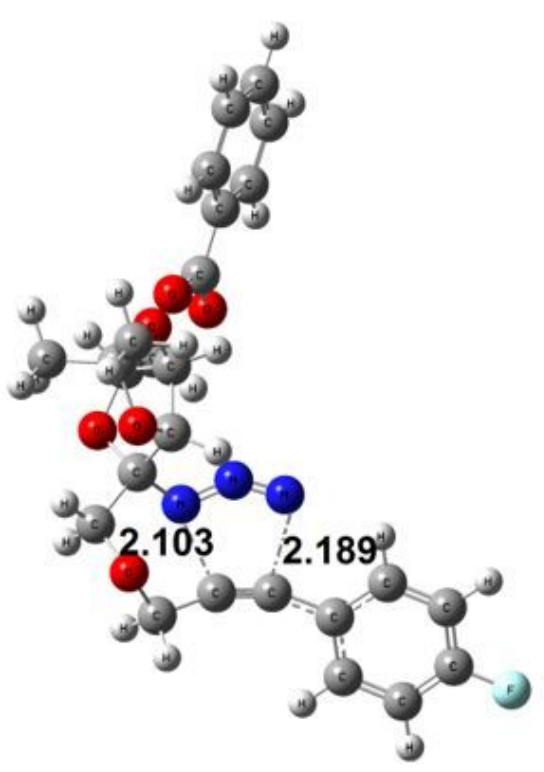

TS2

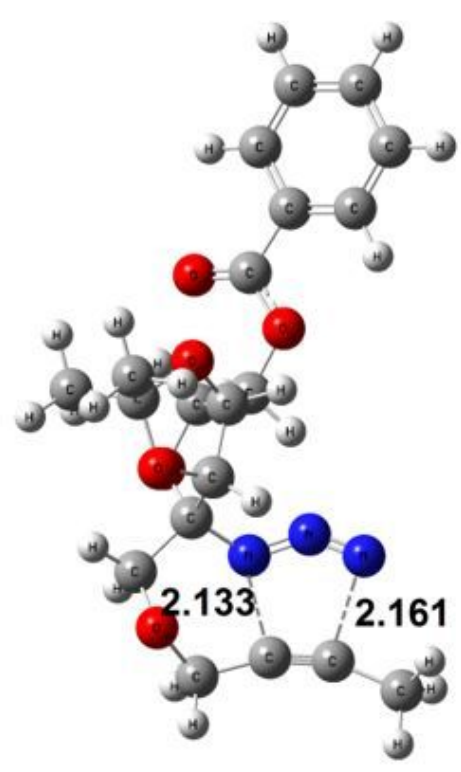

TS3

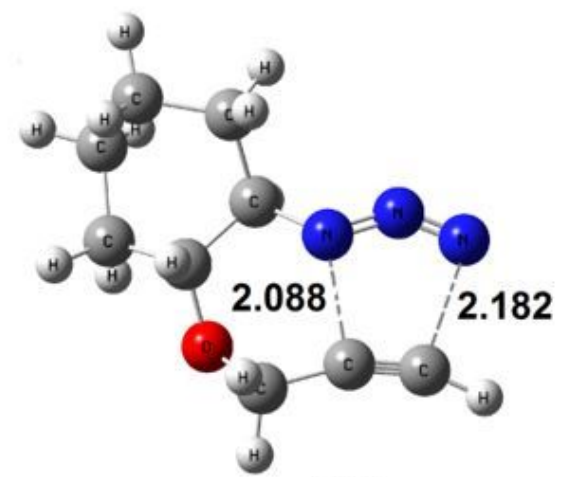

TS4

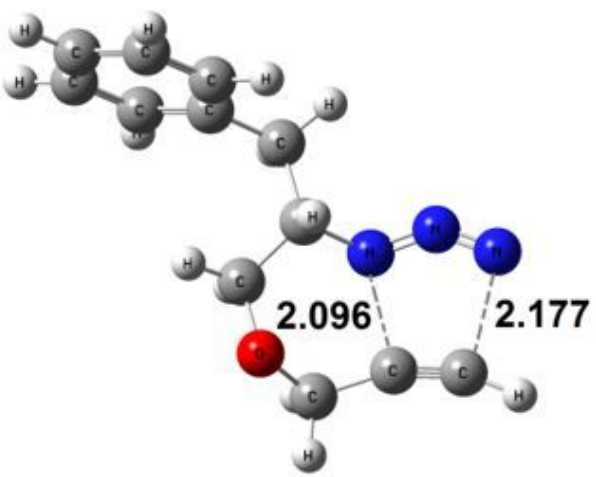

TS5

Figure 3

MPWB1K/6-311G $(\mathrm{d}, \mathrm{p})$ optimized geometries of the TSs associated with the intramolecular 32CA reactions. Bond distances are given in angstrom units. 


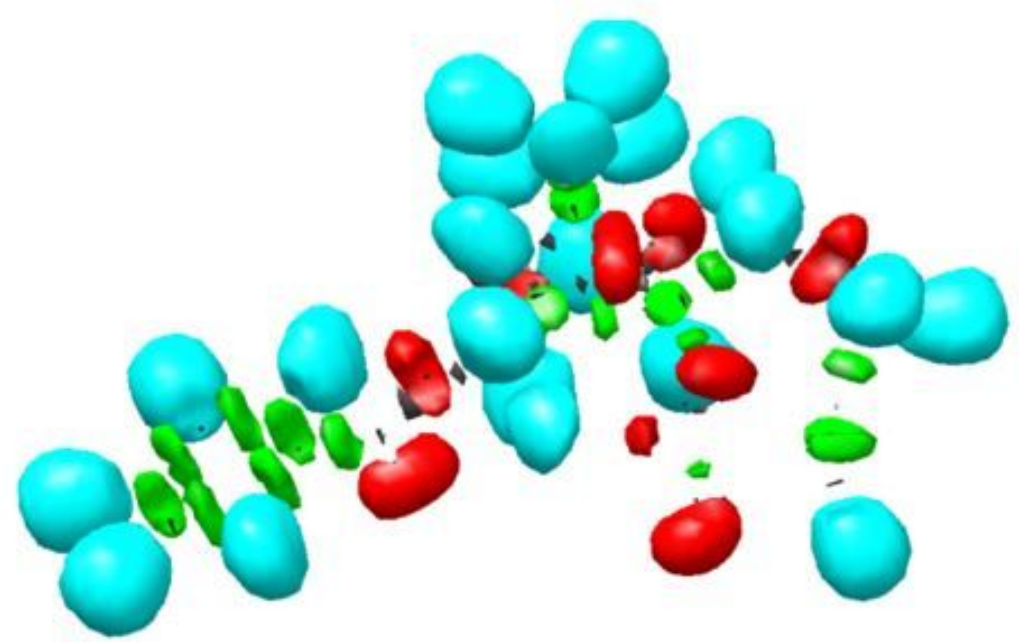

TS1

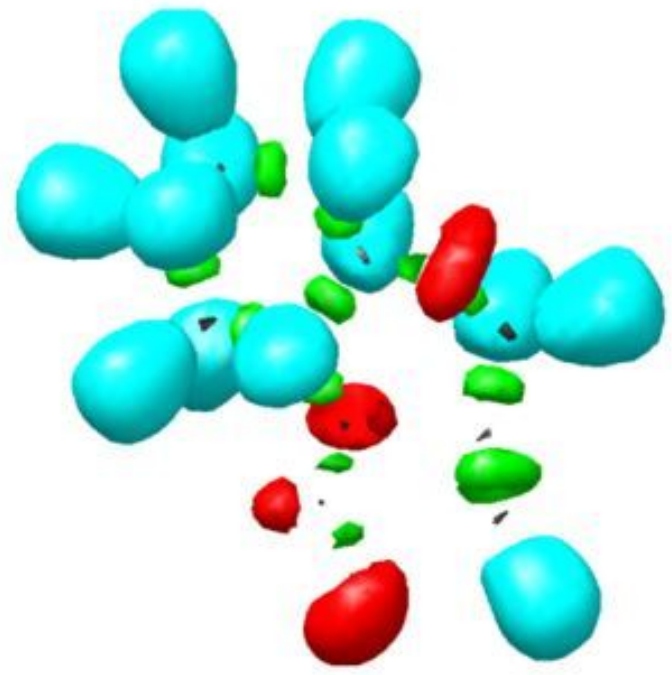

TS4

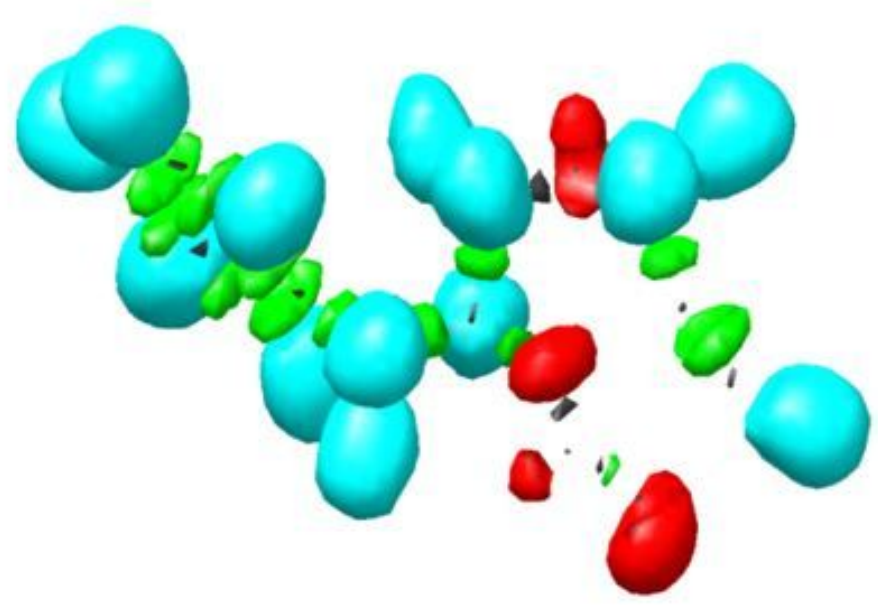

TS5

\section{Figure 4}

MPWB1K/6-311G(d,p) ELF localization domains of TS1, TS4, TS5. Protonated basins are shown in blue, monosynaptic basins in red, disynaptic basins in green and the core basins in black colour (Isovalue = $0.82)$. 


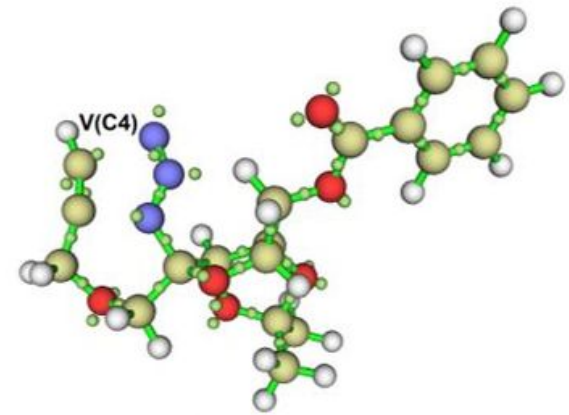

S2

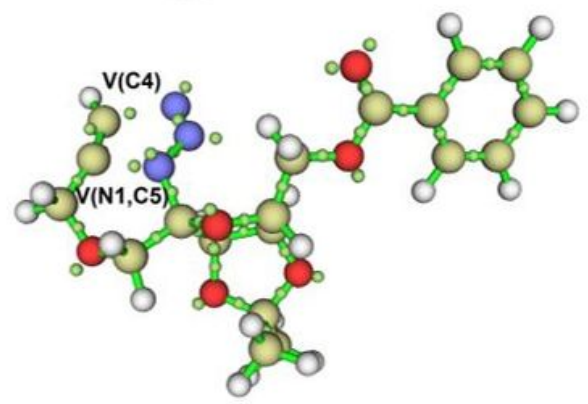

S5

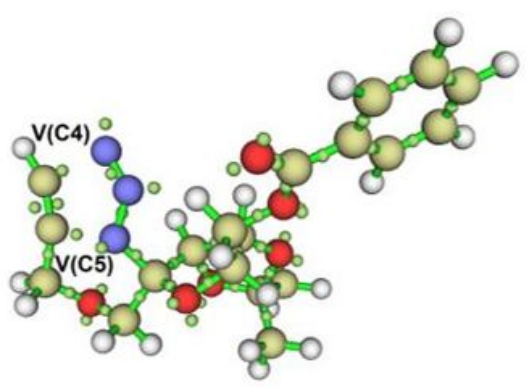

S3

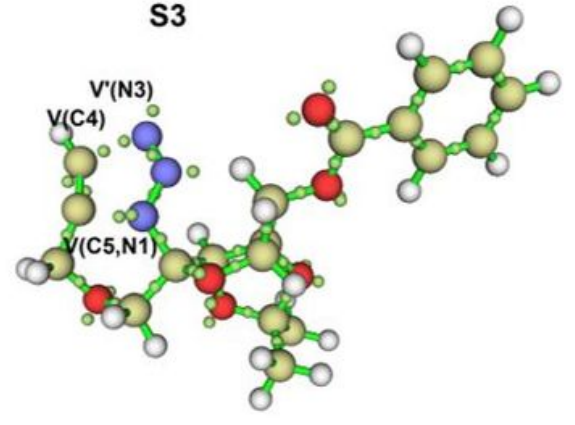

s6

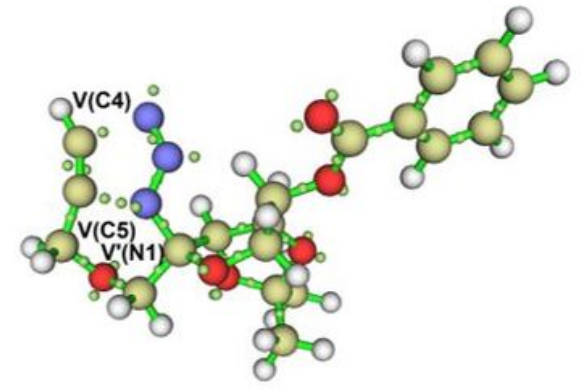

S4

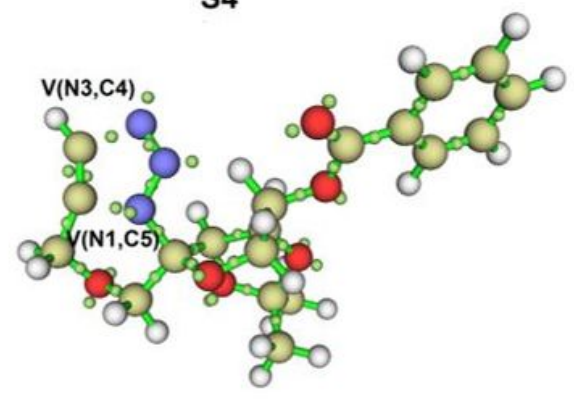

s7

\section{Figure 5}

ELF basin attractor positions at S2-S7 structures associated with the formation of N3-C4 and N1-C5 bonds along the intramolecular reaction of azido alkyne 10

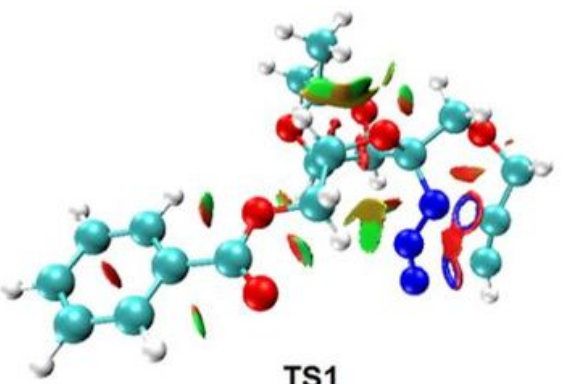

TS1

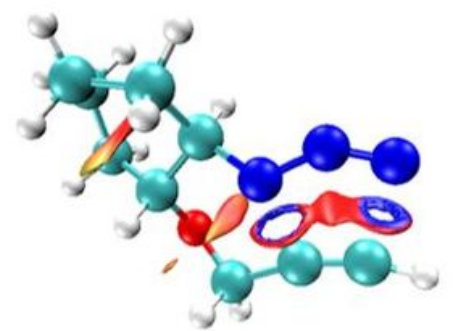

TS4

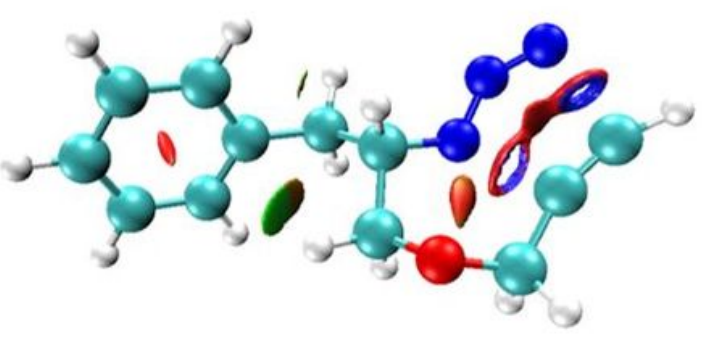

TS5

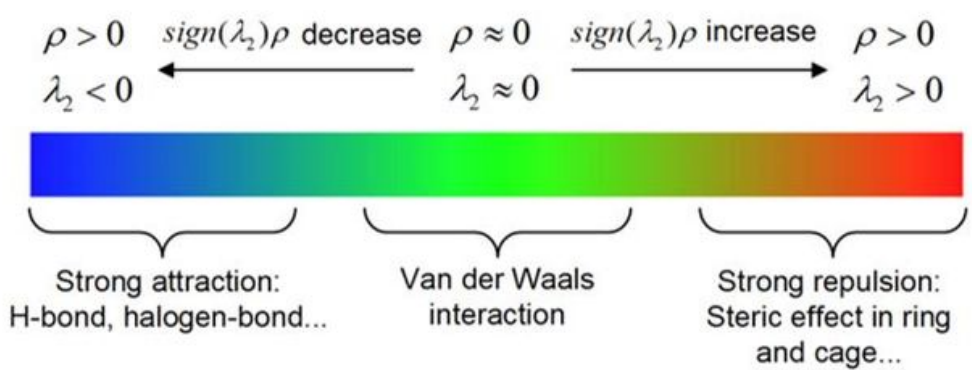

Figure 6

$\mathrm{NCl}$ isosurfaces (Isovalue $=0.01$ ) of TS1, TS4, TS5. associated with the intramolecular 32CA reactions 


\section{Supplementary Files}

This is a list of supplementary files associated with this preprint. Click to download.

- scheme1.jpg

- scheme2.jpg

- scheme3.jpg

- scheme4.jpg

- scheme5.jpg

- scheme6.jpg

- Supplementarylnformation.docx 